\title{
Contexto sócio-histórico das políticas de assistência à infância no Brasil: da caridade ao direito
}

\section{Sociohistorical context of welfare policies to childhood in Brazil: from charity to rights}

Joseana Maria Saraiva ${ }^{1}$

\section{Resumo}

Historicamente, os modelos de atendimento à criança no Brasil como política social têm se caracterizado como um apêndice da área de educação, negligenciando a efetivação do seu direito a uma educação infantil de qualidade. Este estudo tem como objetivo refletir questões centrais acerca da origem, das formas e dos modelos das políticas de assistência à criança no Brasil, considerando os contextos social, econômico, político e cultural em que surgem e evoluem. A perspectiva é apreender essa realidade a partir do período colonial, sobressaindo a compreensão da relação Estado/sociedade na provisão da assistência à criança, por meio das iniciativas não governamentais, religiosas, das organizações filantrópicas e do setor privado lucrativo e sem fins lucrativos para institucionalização da infância. Trata-se de uma pesquisa teórica de abordagem qualitativa, de caráter explicativo, com base em revisão bibliográfica. Apesar dos avanços na legislação que institui a criança como sujeito de direito, bem como de essencialmente necessários ao desenvolvimento integral da criança e da demanda cada vez maior, especialmente, quando o foco é a assistência às classes menos favorecidas, os estudos revelam as carências enfrentadas pelos equipamentos e os serviços de consumo coletivo de atendimento à infância, em particular as instituições de Educação Infantil.

Palavras-chave: Criança. Direitos Sociais. Políticas de Assistência. Contexto sócio-histórico.

\begin{abstract}
Historically, the models of childcare in Brazil as social policy have been characterized as an appendix in the area of Education, neglecting the actualization of their right to a quality early childhood education. The objective of this study is to reflect on central issues about the origin, the forms and the models of childcare policies in Brazil, considering the social economical political and cultural context in which those arise and evolve. The perspective is to learn this reality starting from the colonial period, highlighting the comprehension of the State/society relation in providing assistance to the children, through the nongovernmental, the religious, the philanthropic organizations' and the lucrative and non-lucrative private sector initiatives for the institutionalization of childhood. This is a theorical research with a qualitative approach, of explicative character, based on bibliographical review. Although the advances in legislation which institute the child as a subject of rights, as well as essentially necessary advances to the integral development of the child and the increasing demand, especially, when the focus is the assistance to the poorer classes, the studies reveal the needs faced by the childcare collective equipment and services, specially the institutions of early childhood care.
\end{abstract}

Key-words: Sociohistorical context. Social rights. Care policies. Child.

\footnotetext{
${ }^{1}$ Doutora em Serviço Social pelo Programa de Pós-graduação em Serviço Social da Universidade Federal Pernambuco, Recife, PE. Professora do Departamento de Ciências Domésticas e do Programa de Pós-Graduação em Consumo, Cotidiano e Desenvolvimento Social da Universidade Federal Rural de Pernambuco, Recife, PE. E-mail: joseanasaraiva@yahoo.com.br
} 


\section{INTRODUÇÃO}

A opção por estudar o fenômeno deriva de estudos anteriormente realizados, cujos resultados têm mostrado a insuficiência e inadequação da infraestrutura física, dos materiais e dos equipamentos, aos cuidados e educação da criança. A deficiência vai além desses aspectos, perpassa a oferta de vagas e a qualificação dos recursos humanos apropriados, resultando na baixa qualidade dos serviços prestados aos seus usuários.

Trata-se de uma pesquisa teórica de abordagem qualitativa, de caráter explicativo, que se propôs a refletir questões centrais acerca da origem, das formas e dos modelos das políticas de assistência à criança no Brasil, considerando o contexto social, econômico, político e cultural em que surgem e evoluem. A perspectiva é apreender essa realidade a partir do período colonial, sobressaindo a compreensão da relação Estado/sociedade na provisão da assistência à criança, por meio das iniciativas não governamentais, religiosas, das organizações filantrópicas e do setor privado lucrativo e sem fins lucrativos para institucionalização da infância.

Para tanto, realizou-se uma revisão bibliográfica utilizando as contribuições dos diversos autores que tratam do assunto, por meio de artigos científicos publicados em diferentes periódicos e teses/dissertações de mestrado disponíveis nas bases de dados das bibliotecas das universidades federais, no portal de periódicos da CAPES, Scielo - Scientific Electronic Library Online, dentre outros da área das ciências sociais. Determinou-se como marco cronológico para este estudo o Brasil Colônia, quando surge a preocupação com a assistência à criança em razão das elevadas taxas de abandono em meados do século XVIII, como resultado das novas relações econômicas, políticas e sociais que se estabeleceram entre contingentes populacionais díspares. De posse dos estudos selecionados, procedeu-se à sua leitura e análise integral, visando discutir o fenômeno proposto.

Além do interesse e a experiência da pesquisadora, vale ressaltar a atualidade da questão e sua significação na área da educação, da assistência social e das políticas públicas em geral, que vêm conferindo atenção especial aos direitos da criança, não só em razão dos dispositivos legais que assim o determinam, mas, sobretudo, pelas pressões advindas da própria sociedade, dos movimentos organizados e das reivindicações dos trabalhadores por melhores condições e qualidade de vida.

A produção bibliográfica sobre a questão (OLIVEIRA; FERREIRA, 1986; KRAMER, 1987; CIVILETTI, 1991; HADDAD, 1991; SILVA, 1993; SARAIVA, 1999/2004; KUHLMANN JR, 1990; ROSENBERG, 2001/2003; BRANDÃO, 2003, SARAIVA, 2015; LIMA; SARAIVA, 2017, entre outros) aborda a assistência à primeira infância, valorizando a educação, a saúde, a proteção do 
ser em desenvolvimento e os cuidados requeridos do ponto de vista biopsicossocial. Salienta a instituição de Educação Infantil como necessária na rede de serviços sociais, aponta medidas para aperfeiçoamento da Educação Infantil e chama a atenção para as atribuições e responsabilidades da sociedade e do governo para a importância do processo de cuidados, socialização e educação da criança na primeira e segunda infância como imprescindíveis.

Ao mesmo tempo, esses estudos mostram as carências enfrentadas pelos equipamentos e serviços existentes, apesar da demanda e dos avanços na legislação. A indagação persiste nesse estudo no sentido de entender porque, embora esses equipamentos e serviços sejam oficialmente incluídos nas políticas sociais como "essencialmente necessários ao desenvolvimento integral da criança", como recursos necessários à produção e à reprodução da força de trabalho, contraditoriamente, esses equipamentos e serviços têm se configurado como insuficientes e secundarizados na rede de serviços estatais ao longo da história.

Neste estudo, o foco da investigação recai nos determinantes dessa situação. Por que o Estado deixa em segundo plano ou se omite na provisão desses equipamentos e serviços? A quem interessa o descaso com a Educação Infantil? Muitas explicações têm sido apresentadas, sobretudo na ótica desenvolvimentista, que levam a acreditar num processo linear indutivo, apoiado na mudança de valores ou na vontade política dos dirigentes. Segue-se ainda uma discussão sobre o sistema de proteção social, ora valorizando a intervenção do Estado, ora privilegiando a responsabilidade individual no enfrentamento da questão. Trata-se de serviços sociais ou meios de consumo coletivo indispensáveis ao desenvolvimento integral da criança, à produção do capital e à reprodução da força de trabalho. Contudo, na sociedade capitalista, o Estado tem recorrido a diferentes recursos para tentar garantir a sua existência, embora de forma precarizada.

Nas duas últimas décadas sob influência de ideais neoliberais, ocorre o recuo do Estado enquanto provedor social das políticas sociais, dando lugar ao protagonismo da sociedade civil que passa a responder pelas demandas sociais. O momento é propício à ampliação das parcerias entre o público e o privado, registrando-se o ativismo da iniciativa privada com e sem fins lucrativos que passa a assumir ações de proteção social. A provisão dos serviços sociais coletivos, particularizando, neste estudo, as creches e pré-escolas, continua sujeita a restrições e limites historicamente observados. 


\section{A POLÍTICA DE ASSISTÊNCIA À CRIANÇA: FORMAS E MODELOS DE ASSISTÊNCIA}

Encontra-se na literatura uma diversidade de estudos históricos que tratam da origem, formas e modelos da assistência à criança no Brasil (OLIVEIRA; FERREIRA, 1986; KRAMER, 1987; ROSEMBERG, 1989; KULMANN JR. 1990; CIVILETT, 1991; HADDAD, 1991; SARAIVA, 1999/2015; MARCÍLIO, 2003, dentre outros). A maioria revela que essa preocupação surge ainda no período colonial, em razão das elevadas taxas de abandono de crianças em meados do século XVIII (MARCÍLIO, 2003).

Nessa época, surgem no país as primeiras instituições de assistência à criança, com a implantação das Rodas dos Expostos, da Casa da Roda ou simplesmente Roda: instituição filantrópica onde eram colocados os filhos bastardos ou filhos de escravas, para que estas pudessem exercer a função de amas-de-leite dos filhos das mulheres da casa grande, como diz Freire (2001). A Roda garantia o anonimato do expositor, ao mesmo tempo em que defendia a honra das famílias cujas filhas teriam engravidado fora ou antes do casamento. Além disso, para essa instituição também eram encaminhados os filhos de mulheres livres, em geral pobres, que não tinham sua subsistência garantida.

Recife-PE foi a segunda capital do Brasil a implantar a Casa da Roda, em 1789, na Santa Casa de Misericórdia, e até início do século XIX essa instituição só existia em mais duas capitais, Salvador e Rio de Janeiro. Visando aumentar a oferta, em 1828 as câmaras municipais conseguiram aprovar a Lei dos Municípios, a qual oficializava que em toda cidade onde houvesse uma Santa Casa de Misericórdia, deveria ser instalada uma Roda para assistência aos enjeitados recebidos. Para tanto, a Assembleia Legislativa provincial entraria com um subsídio para auxiliar o trabalho da Misericórdia. Oficializa-se, de certa forma, a participação do Estado na assistência à infância, perdendo-se assim o caráter exclusivamente caritativo para inaugurar uma fase caracterizada como filantrópica, associando-se a esfera pública e a particular.

Os encargos com os expostos eram uma tarefa pesada, custosa e difícil para as Santas Casas de Misericórdia. Dessa forma, assistir às crianças abandonadas sempre foi aceito com muita relutância. Era comum que o espírito de caridade da população ajudasse a manter essas instituições. Muitos proprietários, preocupados com a salvação de suas almas, deixavam em seus testamentos legados e esmolas para as Santas Casas para ajudar na criação de outras casas. Entretanto, ao contrário do que se esperava com a Lei dos Municípios, as Rodas não se multiplicaram, apenas uma dezena delas foi criada em algumas províncias mais importantes. 
Segundo Saraiva (2015), em meados do Século XIX, os higienistas, horrorizados com os altíssimos níveis de mortalidade infantil reinantes dentro das casas de expostos, defendiam sua total extinção. Seguindo os rumos da Europa liberal e a fé no progresso contínuo da ciência, iniciou-se no Brasil uma forte campanha para a abolição da roda dos expostos, considerada pelos médicos higienistas como imoral e contra os interesses do Estado.

Os esforços para extinguir as rodas no país tiveram a adesão dos juristas, médicos higienistas e da Igreja, que começavam a pensar em novas formas e modelos de atendimento para proteger a criança abandonada e para solucionar os problemas oriundos da questão social que começa a perturbar a ordem da sociedade. No entanto, o movimento pela extinção das rodas de expostos não foi suficiente para extingui-las sem resistência. As mais importantes, como as de Salvador e São Paulo, sobreviveram até meados do século XX (MARCíLIO, 2003).

Inúmeras outras instituições de proteção à infância desamparada foram surgindo, porém, a partir do final do século XIX. Em Recife, por exemplo, seguindo o modelo das colônias de Mettray, França, ou de Red Hill, Inglaterra, foi criada em 1888 uma Colônia Agrícola Orphanológica. No Rio de Janeiro, em 1899, o Dr. Arthur Moncorvo Filho fundou o Instituto de Proteção e Assistência à Infância, e em São Paulo, em 1902, o Instituto Disciplinar. A ordem religiosa de caridade de São Carlos fundou, em São Paulo, asilos para os órfãos e os desamparados, filhos de imigrantes europeus, através da iniciativa pública e privada, cujos objetivos eram mesclados da moral cristã da caridade e da filantropia utilitarista, do bom aproveitamento do indivíduo para servir ao capitalismo, aumentando a riqueza do país (op. cit. 2003).

No início do século XX, a filantropia, como modelo assistencial fundamentado na ajuda, começa a substituir o modelo da caridade, de inspiração religiosa. De um lado figuravam necessidades econômicas geradas pela expansão do capital e, de outro, os problemas sociais consequentes da urbanização crescente, criando novos padrões de organização social. Esse quadro passa a ser reconhecido em sua complexidade, principalmente pela classe dominante, como algo que não seria possível controlar de forma individualizada: o problema da assistência à infância deveria ser tratado de forma abrangente, envolvendo a sociedade e o Estado.

A partir de 1930, instituições filantrópicas foram criadas com o objetivo de amparo e assistência à infância pobre e desvalida. As primeiras delas, de grande ação, foram a Liga das Senhoras Católicas e os Centros de Serviços do Rothary Club, em algumas capitais. Posteriormente, em São Paulo, teve atuação notável a Associação Pérola Bygthon (Rizzini,1993). Em Recife-PE, a Liga Pernambucana Contra a Mortalidade Infantil, com o apoio 
do governo estadual, realizava assistência médica domiciliar às lactentes, fornecia medicamentos e alimentos (GOVERNO DO ESTADO DE PERNAMBUCO, 1930, p. 30).

Nesse período, o caráter do atendimento prestado à criança era médico- higienista, ou seja, sustentava a preocupação com os altos índices de mortalidade infantil e se inseria dentro das propostas que integravam o projeto mais geral de saneamento, visando atingir a civilidade e a modernidade, medidas pelos hábitos de higiene e saúde de um povo (SARAIVA, 1999). A medicina desenvolvia-se rapidamente e a pediatria aparecia como um novo ramo da medicina, ocupando-se da puericultura que tratava especificamente do cuidado à criança com normas e regras rígidas. O cuidado de crianças, sem a utilização das regras básicas da puericultura, estaria fadado ao fracasso, podendo acarretar a morte do infante (SILVA, 1993).

Ao analisar as propostas de atendimento à criança no Brasil, na primeira república, Kuhmann (1991) considera que tais propostas resultam da articulação de forças jurídicas, empresariais, políticas, médicas e religiosas, sendo sustentadas por três interesses básicos: além do médico-higienista, o religioso e o jurídico-policial.

A Igreja Católica, fundamentada nos princípios da caridade, no amor ao próximo e na fraternidade, defendia a assistência à infância em prol das classes trabalhadoras, visivelmente menos favorecidas, face às mudanças trazidas pela industrialização do século XIX e pela instalação da nova ordem urbana. Gerou-se então, a necessidade de uma reacomodação de forças, com a igreja buscando-se integrar aos movimentos de assistência às classes menos favorecidas.

Diferentemente da influência médico-higienista e da religiosa, a influência jurídica-policial alertava para o problema da infância moralmente abandonada, tendo em vista evitar a desordem e a criminalidade. Entre as causas atribuídas à época e tais comportamentos, eram destacados fatores hereditários e a influência do meio social, com especial relevo à desorganização da família. Para esse segmento, a absorção da mão de obra feminina pelo mercado de trabalho contribuía para tal desorganização. Entretanto, não sendo possível evitar a saída da mulher do seu domicílio, em razão da necessidade de manter a renda familiar, a criação de equipamentos coletivos de atendimento à criança, como creches, abrigos, escolas maternais, orfanatos, se fazia indispensável, como forma de ajudar os pais trabalhadores.

A assistência à infância garante seu espaço na sociedade brasileira, portanto, na convergência de iniciativas de segmentos da sociedade civil (do setor privado, das instituições religiosas, das associações comunitárias, da organização das damas da sociedade etc.) e sob as determinações das manifestações da "questão social" enunciada com a expansão do capital. O processo migratório seguido da urbanização e da industrialização geraram novas 
necessidades, diversificaram o mercado de trabalho, redistribuíram a divisão social do trabalho na sociedade e incorporaram a mulher ao mercado de trabalho, a fim de garantir a sobrevivência da família. O trabalho da mulher fora de casa, ocupando funções menor remuneradas e desvalorizadas, desencadeia outras situações de carência e de conflitos.

Esse conjunto de situações favorece o crescimento desordenado das cidades, do desemprego, do subemprego, da miséria, aumentando a demanda por serviços e equipamentos sociais. Somando-se a isso, a saída da mulher para o mercado de trabalho e a falta de infraestrutura que the possibilitasse desenvolver suas novas atribuições fora da unidade doméstica ampliam o universo das reivindicações por serviços de consumo coletivos, em particular aqueles voltados para o atendimento à criança, exigindo um posicionamento do Estado.

\section{A PRESENÇA DO ESTADO}

Embora algumas instituições oficiais destinadas à proteção da criança tenham sido criadas antes dos anos 1930, é importante ressaltar que só a partir de 1940 o Estado brasileiro passou efetivamente a contribuir para o desenvolvimento dessas instituições. Em nome da assistência e proteção à maternidade e a infância, passou então a dividir com as organizações privadas a responsabilidade de custeio e controle da prestação de serviços socais. Sua proposta consistia em equipar as instituições de atendimento à infância com pessoal qualificado na área de saúde para execução das ações, seguindo a perspectiva médica-higienista, com funções de prevenção e assistência. O caráter do atendimento era exclusivamente médico, justificado como forma de remediar e socorrer a criança da situação de abandono em que se encontrava. Culpavase a família pelas condições de vida propiciadas à criança, camuflando-se as diferenças sociais produzidas pela distribuição de renda desigual.

A partir desse período, observa-se uma mudança qualitativa no comportamento assistencial do Estado e do empresariado em relação aos trabalhadores urbanos (VIEIRA, 1988). Segundo Kramer (1987), a necessidade de preparar a criança de hoje para o homem de amanhã, futuro trabalhador, mostrou-se importante para fortalecimento do próprio Estado Nacional, tornando-se um dos principais fatores que levaram os setores públicos a valorizar a proteção e a educação das crianças de 0 a 6 anos.

Nesse período, manifestos organizados foram realizados reivindicando vantagens trabalhistas, serviços sociais ou protestando contra as precárias condições de vida e de trabalho a que as mulheres se achavam submetidas: inexistência de assistência médica, habitação 
precária, falta de infraestrutura sanitária, além de baixos salários, jornadas excessivas de trabalho e insalubridade. Foram reivindicados também equipamentos para atendimento à criança como uma medida urgente a ser tomada pelo governo e empresários, devido às longas jornadas de trabalho das mulheres (OLIVEIRA; FERREIRA, 1986).

Com a intensificação do clima de tensão no país, o governo, na tentativa de manter a ordem social, se dispôs a fazer algumas concessões aos trabalhadores, incluindo o atendimento à criança em creches. Assim, em 1943, o Estado cria dispositivos legais na CLT (DL005.452.1943, Art. 389) determinando a instalação de creches nos locais de trabalho, a cargo do empregador. Surge, então, a primeira lei no país que determinava a criação de creches, assim formulada: "o estabelecimento em que trabalhe pelo menos 30 mulheres, na faixa etária entre 16 e 40 anos de idade, é obrigatório possuir um local apropriado onde as funcionárias possam guardar, sob vigilância e assistência, seus filhos, no período da amamentação" (CLT, 1943).

Na prática, essa lei nunca foi aplicada e nem respeitada pelos empregadores, restringiase ao período em que a criança era amamentada (6 meses). Cessada a amamentação, a empresa desobrigava-se de manter a creche em funcionamento e a criança passava a ser responsabilidade exclusiva da mãe, inviabilizando que a mesma continuasse trabalhando. Em 1967 o texto da CLT sofre modificações, desobriga as empresas da manutenção de creches, ao facilitar o direito de optarem por convênio com outras instituições similares, para esse fim. $\mathrm{Na}$ prática, essa opção tornou-se inviável, em razão do tempo permitido pelas empresas, de apenas 30 minutos, para a trabalhadora amamentar o filho.

Além de intervir na CLT, o Estado procurou instituir, em nível de aparato técnicoburocrático, órgãos que centralizassem a assistência à mãe e à criança. As creches, integrando uma política de proteção à maternidade e à infância, ficaram ligadas aos órgãos da área de saúde e assistência social. Entre as instituições assistenciais podem-se destacar: o Conselho Nacional de Serviço Social do Ministério da Educação e Saúde, criado em 1938; o Serviço de Assistência ao Menor - SAM (1941), que visava atender a criança abandonada e delinquente, vinculado ao Ministério da Justiça e Negócios Interiores; o Departamento Nacional da Criança DNCr (1941), do Ministério da Educação e Saúde; a Legião Brasileira de Assistência - LBA (1942), que se propunha a assistir a família dos expedicionários durante a guerra. Ademais, instituiu o Serviço Social do Comércio - SESC (1946) e o Serviço Social da Indústria - SESI (1946), ambos de iniciativa patronal, mas de interesse do governo, que se ocupavam igualmente da atenção à maioridade e a infância junto às categorias de trabalhadores dos setores do comércio e da indústria, respectivamente. 
No pós-guerra, com a instalação do UNICEF no Nordeste (1955), a assistência maternoinfantil ganha especial relevância, com foco principal no controle e erradicação de doenças e promoção da saúde da gestante e da criança, e mantém como prioridade o programa de alimentação complementar por meio da distribuição de leite em pó às famílias pobres da região, através dos serviços sociais públicos. Nessa condição, até os anos 1960, o Estado não produzia planos ou programas nessa área, não dimensionava custos, metas, não planejava o atendimento à criança, respondia apenas a demandas isoladas.

A participação ativa e a boa vontade de segmentos da sociedade - profissionais de diversas áreas, intelectuais, autoridades públicas, grandes empresários, lideranças religiosas e outros grupos continuaram imprescindíveis para atingir os fins da assistência à criança. Caberia ao Estado articular esses segmentos, sobretudo, os mais afortunados, para que os problemas das crianças fossem superados.

Assim, o modelo de atuar do DNCr era baseado na criação de equipamentos públicos coletivos, principalmente os chamados postos de puericultura, onde as mães deveriam receber, além de orientação médica desde o início da gravidez, medicamentos e alimentos. Após o parto, seguia-se o acompanhamento da criança até a fase escolar, quando entraria em cena a Casa da Criança, um tipo de escola com orientação médica- higienista. Em Pernambuco, na década de 1960, o Governo do Estado evidencia, em relatório ao Presidente da República, a existência desses postos, os quais distribuíam leite para as crianças pobres, cujas mães não amamentavam (GOVERNO DO ESTADO DE PERNAMUCO, 1965). Segundo Pereira (1997), além dos postos de puericultura, o programa integrava outros equipamentos como os lactários, as escolas maternais, as creches, os jardins de infância, os parques infantis e as casas das crianças, cujo funcionamento se dava na mesma perspectiva dos postos de puericultura propostos pelo $\mathrm{DNCr}$ como forma de remediar e socorrer a criança em situação de vulnerabilidade social. Com essa preocupação, as creches eram defendidas como elementos da puericultura social, únicos estabelecimentos capazes de combater eficazmente o comércio da criadeira.

A ação estatal na área da educação infantil caracterizou-se pela execução indireta, na forma de convênios e de associação com instituições particulares de caráter filantrópico, leigo ou confessional, que mantinham creches e programas assemelhados em funcionamento. Tanto - DNCr como a LBA funcionavam como órgãos repassadores de recursos para essas instituições, monitorando ações e resultados. A LBA chegou a implantar efetivamente creches ou casas da criança diretamente, em vários estados do Brasil, mas prevalecia a execução em parceria, mediante convênios. O DNCr constituía o órgão normativo, encarregado da formulação de diretrizes e procedimentos para assegurar o adequado funcionamento das creches, enquanto 
unidade de prestação de serviços à criança, encarregando-se também da fiscalização e de publicações de manuais de orientação que fundamentavam a organização dos serviços e seus objetivos, do ponto de vista sanitário, do desenvolvimento da criança e suas necessidades, da preparação do pessoal responsável e os aspectos arquitetônicos das instalações. Orientações que ficaram registradas apenas no papel e no discurso, uma vez que, na prática, as creches continuavam reproduzindo a precariedade das condições em que a criança e sua família já enfrentavam em casa (OLIVEIRA; FERREIRA, 1986).

Embora consideradas "um mal", na medida em que sua existência nos grandes centros urbanos (Rio de Janeiro e São Paulo, especialmente) revelava desorganização social, desajustamento moral e econômico, as creches eram vistas como indispensáveis, principalmente por se constituírem alternativas higiênicas às criadeiras. Além disso, a creche era útil como instrumento essencial às mulheres pobres e desamparadas. Um recurso ligado à pobreza. As creches recorriam às mulheres forçadas a trabalhar: mães solteiras, mulheres abandonadas por seus companheiros, viúvas e mulheres casadas que contribuíam com seu trabalho para aumentar o orçamento familiar.

Um dos estados do Brasil que avançou no atendimento dessas reivindicações foi Pernambuco. Em 1935, conforme registro encaminhado ao Chefe Provisório da República, à época, o Sr. Getúlio Vargas, o Governo do Estado de Pernambuco destacava, dentre outras obras realizadas diretamente pela Liga Pernambucana Contra a Mortalidade Infantil, a existência de lactários nas fábricas localizadas nos bairros da Várzea, da Torre e de Moreno, onde os operários deixavam seus filhos sob os cuidados de uma enfermeira orientada por um médico. Nesse mesmo documento, o governador reconhece essa iniciativa como de grande alcance e valor, ressaltando seus benefícios diante de um dos problemas mais delicados da época: o da higiene e assistência à criança (GOVERNO DO ESTADO DE PERNAMBUCO, 1935).

No regime militar, a reestruturação dos serviços assistenciais se estende, ainda, ao Serviço de Assistência ao Menor - SAM, substituído pela Fundação Nacional do Bem-Estar do Menor-Funabem (Lei Federal 4.513 de 01/12/1964), que assumiu a competência de formular e implantar a Política Nacional do Bem-Estar do Menor em todo o território nacional. Cabia às unidades estaduais a execução dos programas de atendimento à criança e ao adolescente com observância dos princípios definidos na política nacional de bem-estar do menor, prevenindo a marginalização e oferecendo oportunidades de promoção social (FIA, 2007).

A partir dos anos 1970, frente à situação do contingente de crianças em idade pré-escolar, ao déficit de escolas maternais, de creches e jardins de infância, o DNCr muda seu discurso com ênfase no rigor higiênico, tendo em vista combater a desnutrição, a mortalidade infantil e as 
criadeiras, e propõe, junto com o UNICEF, a ampliação do atendimento de 0 a 4 anos para 0 a 6 anos de idade. A nova demanda seria atendida em centros de recreação modestos que poderiam ser instalados em áreas cedidas pelas igrejas ou ainda em equipamentos comunitários, funcionando com a participação de pessoal voluntário. Para tanto, esses órgãos conclamavam a participação da comunidade, mães e jovens, para manter os serviços através da arrecadação de fundos nos centros. As propostas do DNCr de creches/pré-escolas, com pessoal qualificado, infraestrutura física e material adequados e de maiores verbas para a manutenção dessas instituições, cedem lugar às propostas simplificadas de atendimento à criança com a participação da comunidade, segundo um modelo assistencialista e emergencial.

Essas propostas simplificadas passam a ser desenvolvidas no Recife e em outros estados do Nordeste e do Brasil, a partir da iniciativa de associações particulares, sem a participação do Estado, como alternativa à falta de serviços públicos. No início dos anos 1960, a cidade contou com 4 parques de recreação e 16 cantinas, mantidos pela Campanha Pernambucana PróInfância, entidade organizada pelas senhoras da sociedade pernambucana. Os Parques de Recreação Infantil prestavam assistência às crianças em período integral, incluindo, além dos cuidados físicos, três refeições diárias. Através das cantinas, cerca de cinco mil crianças recebiam alimentação, roupas, assistência médica, educação cívica e religiosa (GOVERNO DO ESTADO DE PERNAMBUCO, 1961).

Esse tipo de atendimento prestado à criança foi proposto aos Governos dos países do Terceiro Mundo por organismos internacionais - o Fundo das Nações Unidas para a Infância (UNICEF), o Fundo das Nações Unidas para Alimentação (FAO), a Organização Mundial de Saúde (OMS), a Organização Pan-Americana de Saúde - como forma de resolver os problemas do subdesenvolvimento a que se atribuía a falta de assistência e serviços na área de saúde, nutrição e educação da criança. Isso porque o desamparo de populações pauperizadas do Terceiro Mundo poderia ameaçar a ordem capitalista e abrir caminho para o desenvolvimento e a penetração de ideologias revolucionárias, a exemplo do que havia ocorrido em Cuba (VIEIRA, 1988).

O conceito de creche como mal necessário começa a ceder lugar a um conceito de atendimento, onde se busca, junto às crianças, compensar carências diversas e oportunizar o trabalho da mulher fora do lar. A participação da mulher na população economicamente ativa aumenta significativamente. Nesse momento, a creche se mostra como um importante dispositivo para alimentar crianças pobres, desnutridas ou potencialmente desnutridas, além de suprir outras necessidades, inclusive afetivas, emocionais, não mais asseguradas pela família. Para tanto, procura-se, nesse "novo" contexto, incitar a participação comunitária e ampliar a 
assistência estatal através de convênios com entidades sociais filantrópicas e com organizações comunitárias de cunho popular.

As bases desse modelo de atendimento tinham como fundamento as teorias psicopedagógicas da privação cultural, atribuindo ao ambiente social "desagregador" gerado pela miséria a responsabilidade do "desajuste social", do baixo desempenho produtivo em alguns setores, do fracasso escolar, enfim, da gritante "marginalidade" socioeconômica em que se encontravam largos setores da sociedade brasileira (SARAIVA, 1999). No Brasil, as teorias da privação cultural influenciaram os discursos oficiais e os diversos programas de atendimento à criança pré-escolar, dentre os quais o Projeto Casulo, implantado pela LBA.

Como instituição mais diretamente ligada à assistência social, a LBA desenvolveu, a partir de 1977, o Projeto Casulo, considerado o primeiro programa brasileiro de educação infantil de massa e assistência integral à criança. Seu objetivo consistia em atender com pouco gasto o maior número possível de crianças na faixa etária de 0 a 6 anos de idade, tendo em vista prevenir a marginalização e deixar as mães com maior tempo livre para trabalhar fora e elevar a renda familiar. Nessa perspectiva, sua tônica recaía no atendimento às carências nutricionais das crianças, que permaneciam de 4 a 8 horas diárias nas sociais onde o projeto era desenvolvido, recebendo alimentação, cuidados físicos e material didático (ABRANTES, 1991).

Para tanto, o projeto privilegiava a participação da comunidade como forma de custeio, argumento legítimo para diminuição de custos e atendimento de um maior número de crianças possível (ROSEMBERG, 2003). Nesta condição, o quadro de pessoal das instituições, na sua maioria, se constituía de voluntários oriundos da própria comunidade, e a infraestrutura física e material, além de insuficiente, se mostrava inadequada aos objetivos propostos. Contudo, o projeto efetivamente implantado em menos de 4 anos já atendia mais de um milhão de crianças pobres em todo Brasil, em diversos municípios. Para Rosemberg (2003), essa expansão se deu às custas de uma estratégia bem brasileira: ampliar o número de crianças atendidas e reduzir o custeio federal, produzindo um atendimento pobre para pobre.

Os diversos estudos acerca do Projeto Casulo são unânimes em afirmar que este projeto só teve condição de ser implantado em larga escala porque se coadunava e se constituía como expressão da Doutrina Brasileira de Segurança Nacional (DSN), primeiro regime de Segurança Nacional instalado na América Latina em 1964, particularmente porque, ao adotar o discurso da prevenção, propiciava uma entrada direta e visível do governo federal no nível local, sem passar pelas administrações estaduais. Baseava-se em pequenos investimentos orçamentários, apesar de ser um programa de massa, adotando a estratégia de participação da comunidade, ajustandose assim ao modelo econômico preconizado pelo Estado de Segurança Nacional. Nesse sentido, 
um modelo "antissocial", cuja preocupação maior centrava-se na ideia de transformar o Brasil numa potência econômica.

O Projeto Casulo permitiu uma entrada direta do governo federal em um grande número de municípios espalhados pelo território nacional, privilegiando a participação da comunidade, incluindo seus recursos e a mobilização de entidades particulares. Isto pode ser comprovado por meio dos dados da cobertura de atendimento nacional à criança em creche e pré-escola através da LBA no período de 1977 a 1990. No primeiro ano de sua implantação a LBA atendia 21.280 crianças, em 725 creches/pré-escolas espalhadas em 243 municípios; em 1990 esse número sobe para 1.602.261 crianças atendidas, em 23.265 instituições e 3.286 municípios (LIMA, 1990).

Contudo, a primeira avaliação do Projeto Casulo, efetuada no ano seguinte a sua implantação, evidencia sérios problemas estruturais, em grande parte atribuídos à tônica de eficiência buscada pelo modelo. Dentre outros, a própria LBA destaca a falta de pessoal qualificado; inadequação do espaço físico e dos materiais e falta de água nos locais em que a creche ou pré-escola era implantada. Dificuldades que comprometiam o desenvolvimento das atividades, tanto do ponto de vista pedagógico como assistencial.

A partir desse modelo, na perspectiva de compensar carências diversas (econômicas, alimentares, nutricionais, psicológicas, motoras e sociais), uma rede de creches e pré-escolas de origem comunitária e com objetivos filantrópicos foi implantada em várias capitais do País, inclusive no Recife. Contudo, essas instituições tinham em comum o baixo padrão de qualidade, caracterizado pelo baixo nível de escolaridade e de qualificação do quadro do pessoal, e pelos produtos e serviços oferecidos à criança. Além disso, pelo contexto urbano onde se localizavam, vilas, favelas, áreas de periferias mal servidas de água e esgoto e outros serviços complementares, muito pouco era possível realizar em favor do desenvolvimento das crianças atendidas (VIEIRA, 1988; HADDAD, 1989; LIMA,1990; SILVA, 1993; SARAIVA, 1999).

A situação persiste, em pleno século XXI. No seu parecer ao Plano Nacional de Educação (2000), o senador José Jorge salienta que a grande maioria das creches e pré-escolas não conta com infraestrutura física adequada, com profissionais qualificados, não desenvolve programas educativos, não dispõem de mobiliário, brinquedos e outros materiais pedagógicos adequados e indispensáveis ao desenvolvimento da criança, além de que grande parte das crianças, na faixa etária que seria assistida por estas instituições, era assistida por instituições filantrópicas e associações comunitárias que recebiam apoio financeiro de algum órgão público (PLANO NACIONAL DE EDUCAÇÃO, 2000, p. 45).

O que se pode depreender, a partir do que os estudos apresentam, é que o atendimento à criança em creches e pré-escolas públicas continua a ser prestado pelo aparato estatal e pela 
sociedade como uma solução remediadora da extrema situação de pobreza em que vivem as famílias, uma possibilidade que lhes é dada para que seus filhos não se tornem futuros marginais. Nessa ótica, a creche ou a pré-escola é apenas o lugar que vai assistir, alimentar, proteger e guardar a criança pobre para que a mãe possa trabalhar. Para os próprios profissionais que trabalham nessas instituições, a creche foi e continua sendo entendida como um favor à família (ROSSETI; OLIVEIRA,1986; COSTA 1981; SARAIVA, 2004; LIMA, 2016).

É possível afirmar que se trata de tendência que reproduz o modelo de Estado vigente sob influência das ideias neoliberais, mais preocupada com os resultados econômicos, ficando os interesses e necessidades sociais da população em segundo plano. No campo específico das políticas sociais voltadas para o atendimento à criança, se resumiram a programas assistencialistas, de auxílio à pobreza, e de modo complementar à filantropia privada, utilizando práticas clientelistas e compensatórias, de baixo custo, mobilizando os recursos comunitários por meio da ajuda mútua. Modelos que não produziram impactos significativos nas condições de vida das famílias e, por conseguinte, na proteção social à criança. Em especial, a primeira infância.

\section{O ACESSO ÀS POLÍTICAS DE ASSISTÊNCIA À CRIANÇA: UM DIREITO EM CONFLITO COM A REPRODUÇÃO DAS RELAÇÕES SOCIAIS}

Ao discutir as políticas de assistência e atendimento à criança não se pode deixar de considerar o papel desempenhado pelos movimentos sociais, liderados pelas mulheres das periferias dos centros urbanos.

Nas duas últimas décadas do século passado, a necessidade fez com que as mulheres da periferia de São Paulo se organizassem, principalmente através dos Clubes de Mães que faziam parte das Comunidades Eclesiais de Base (CEBs), a fim de reivindicar ao poder público equipamentos onde pudessem deixar suas crianças enquanto trabalhavam. Nos grandes centros urbanos do país, o movimento se expandiu e se intensificou com a adesão dos operários, dos grupos feministas e de intelectuais, possibilitando a unificação da luta e também seu alcance social. Com o apoio da classe trabalhadora, o movimento adquire novas conotações e muda o enfoque da reivindicação, passando as mulheres a defender a instituição creche não mais como um local destinado a guarda e à sobrevivência de crianças pobres, mas como um direito da criança, independentemente de sua condição econômica.

Em Pernambuco, o movimento e suas principais reivindicações são determinados, prioritariamente, pela luta das mulheres trabalhadoras em defesa de melhores condições de vida. 
Com esse objetivo, se mobilizam e conseguem criar creches e pré-escolas nas áreas mais carentes com o apoio de associações de moradores, igreja, clube de serviços e outras entidades, baseadas na função reconhecida de guarda e assistência às crianças pobres. Mesmo com instalações precárias, sem os equipamentos necessários, mantidas com pessoal voluntário e, muitas vezes, de baixa escolaridade, sem formação profissional, foram implantadas as primeiras creches, que se reproduziram mediante convênios com o governo e ONGs que atuavam como órgãos repassadores de recursos.

Embora reconhecida como um recurso de uso coletivo ligada à reprodução da força de trabalho, observa-se que o acesso à creche pela população é muito restrito. Conforme registram Azevedo e Antunes (1990), em 1985 a Prefeitura da Cidade do Recife- PCR atendia um total de 1.190 crianças em 13 creches, não dispondo de dotação orçamentária para mantê-las dentro dos padrões de qualidade aceitáveis. $\mathrm{Na}$ administração seguinte, sob a pressão e luta dos movimentos organizados, foi incluído no plano assistencial da Prefeitura o Programa Creche Popular, que valoriza a creche como um polo irradiador das ações culturais, educativas, de saúde e de lazer, buscando uma organização descentralizada e a integração das ações assistenciais no município. Funcionando num regime de cogestão, os espaços físicos seriam encontrados na própria comunidade, bem como os funcionários; as mães das crianças assistidas pela própria instituição assumiriam as funções em forma de rodízio; o apoio técnico seria dado através de uma equipe da prefeitura, volante e multidisciplinar. Em outros termos, a creche é incluída como recurso de geração de renda para família, sob o manto do voluntariado. À medida que a mãe participava do trabalho na instituição, contribuía com o orçamento doméstico, diminuindo assim as despesas, principalmente com sua alimentação e da criança. O relatório da administração municipal registra, no final de 1989, o total de 19 creches, atendendo cerca de 2.090 crianças. Para a gestão da PCR, na época, este número é configurado como um referencial de avanços em assistência à criança.

Estas creches, entretanto, funcionavam em estado de extrema precariedade e muitas delas acabam fechando. A falta de infraestrutura física e material, bem como de pessoal qualificado, são questões ressaltadas pelo I Seminário Estadual sobre creches (1990) ao reivindicar que o atendimento à criança de 0 a 6 anos seja de fato considerado prioritário pelo Estado, e que medidas urgentes fossem tomadas nesse sentido.

No contexto nacional, a proposta do movimento de luta por creche era a criação de uma rede mantida totalmente pelo Estado (HADDAD, 1991). Em São Paulo, essa proposta ganhou força expansiva, ainda que baseada na sua função reconhecida de guarda e assistência a crianças pobres, literalmente confirmada pelo critério de seleção, priorizando a renda familiar de 
zero a três salários mínimos, nivelando a clientela de creche pelos mais baixos níveis de pobreza, prevalecendo a perspectiva assistencialista, seguindo a linha da educação compensatória.

Uma nova realidade no campo de atendimento à criança de 0 a 6 anos se apresenta com a Constituição de 1988. A pressão unificada dos vários setores da sociedade junto à Assembleia Constituinte resultou na aprovação do artigo 208 que determina o direito à educação das crianças de 0 a 6 anos em creches e pré-escolas; o direito dos trabalhadores, homens e mulheres, a creches e pré-escolas, a assistência gratuita aos filhos e dependentes desde o nascimento até os 6 anos de idade; o dever do Estado para com os cuidados e a educação da criança pequena. O conjunto desses direitos, reunidos, transformou-se no Estatuto da Criança e do Adolescente ECA, a partir da Lei $n^{\circ}$ 8.069, de 13 de julho de 1990, que no Capítulo IV, Art. 54, parágrafo IV assegura atendimento em creche e pré-escola às crianças de 0 a 6 anos de idade.

Pode-se considerar que, na legislação, a inclusão de creche no campo do direito à educação significou um grande avanço; veja-se, por exemplo, na Consolidação das Leis do Trabalho - CLT, de 1943, a creche figurava como atribuição do empregador apenas em empresas onde trabalhassem pelo menos 30 mulheres, com mais de 16 anos de idade, como local para as empregadas guardarem seus filhos durante o período da amamentação (DL - 005452, 1943, Art. 389, parágrafo $1^{\circ}$ ). A Lei 4.024/61 não fazia qualquer menção sobre a matéria. A Lei nº 5692/71 dedicou à educação infantil apenas um parágrafo sobre o tema, atribuindo ao Estado o papel de "velar" para que os sistemas de ensino oferecessem atendimento em jardins de infância ou similares. Dessa forma, a creche, junto com a pré-escola, inaugura na Constituição de 1988 e no ECA sua presença na legislação, na esfera educacional.

A educação das crianças de 0 a 6 anos, antes concebida como amparo e assistência, passou a figurar como direito da criança e dever do Estado, em resposta aos movimentos sociais em defesa dos direitos das crianças. Nesse contexto, a proteção integral às crianças deve ser assegurada com absoluta prioridade, pela família, pela sociedade e pelo poder público. A Lei afirma, portanto, o dever do Estado com a educação das crianças de 0 a 6 anos (BRASIL, 2003, p.8).

A década de 1990 iniciou-se sob a égide do dever do Estado perante o direito da criança à educação, explicitado na Constituição Federal e reafirmados pelo ECA (1990). Em 1994 é aprovada a Política Nacional de Educação Infantil, na qual se definem como principais objetivos: a expansão da oferta de vagas para a criança de 0 a 6 anos; o fortalecimento, nas instâncias competentes, da concepção de educação e cuidados como aspectos indissociáveis das ações dirigidas às crianças e a promoção da melhoria da qualidade do atendimento em creches e préescolas (BRASIL, 2004). O documento enfatiza a necessidade de integração de esforços no 
sentido de otimizar os meios e resultados na consolidação de alianças entre Governo, organizações não governamentais e representantes da sociedade civil para que estes objetivos sejam alcançados. Considera ainda que as ações prioritárias devem ser objeto de acordos e parcerias entre os diferentes atores que se envolverão no processo de cuidados e educação da criança.

Em 1995, o Ministério da Educação definiu a melhoria da qualidade do atendimento dos cuidados e educação da criança nas creches e pré-escolas como seu principal objetivo. Esse objetivo é reafirmado com a aprovação da nova Lei de Diretrizes e Bases da Educação Nacional (Lei 9394/96), segundo a qual a Educação Infantil passa a ser considerada como primeira etapa da Educação Básica, destinada às crianças de 0 a 6 anos de idade, devendo ser oferecida em creches e pré-escolas, cumprindo duas funções básicas complementares e indissolúveis: cuidar e educar, complementando os cuidados e a educação da criança realizada pela família (BRASIL, 2004).

A Educação Infantil passa, então, a ser entendida como resultado das atividades de cuidados físicos inerentes à alimentação, higiene, segurança e preservação da saúde da criança, bem como aquelas relacionadas a seu desenvolvimento motor, cognitivo, social e afetivo, atividades antes concebidas de forma desarticulada e hierarquizada, uma vez que os cuidados físicos (com a higiene, alimentação, nutrição, saúde) historicamente predominavam nos objetivos e no funcionamento destas instituições.

A partir dessas considerações, é possível perceber os avanços no campo dos direitos da criança e sua relação com as condições históricas do País. Para Silva e Silva (2001), pelo menos no aspecto formal, a política de atendimento à criança, no Brasil, torna-se bastante diferenciada da sua perspectiva original, haja vista que se tem hoje uma política de cuidados e educação da criança específica, dirigida à infância. Entretanto, entre o disposto na lei e o efetivamente assegurado existem ainda profundas lacunas, seja quanto à disponibilidade dos serviços, seja quanto às condições de creches e pré-escolas desenvolverem um modelo de atendimento redimensionado, pautado nos princípios da política de defesa e de proteção integral à criança.

Analisando a política de educação infantil, Brandão (2003) salienta a sua ineficácia em relação à expansão da oferta de vagas, cujos impactos têm sido limitados. Enfatiza que o número de crianças sem acesso à educação infantil no Brasil é muito grande, exigindo medidas urgentes. No que concerne ao atendimento na rede pública, baseado nos dados apresentados pelo MEC/INEP (2004), constata-se uma redução no atendimento, particularmente na faixa etária de creche: 0 a 3 anos. Para se ter uma ideia, o número de crianças atendidas em creches, no País, 
caiu de 1.652.337 em 1994, para 1.309.985 em 1999, indicando que não houve progresso em relação ao atendimento da demanda existente.

Corroborando a análise de Brandão, dados da PNAD (2006), pesquisa de amostra de domicílios (IBGE/ PNAD, 2006) mostram que o acesso à educação infantil, embora de fundamental importância para garantia do desenvolvimento pleno da criança, ainda está muito aquém das necessidades do País. No Brasil, a população de crianças até 6 anos é de aproximadamente 23 milhões, equivalente a 11\% da população brasileira. Destas, apenas 15,5\% (1,5 milhão) de até 3 anos frequentam creches. No Nordeste esse percentual cai para 13\%, são quase quatro milhões de crianças na faixa etária de creches ( 0 a 3 anos), que não frequentam essa instituição (IBGE/PNAD, 2006).

No Nordeste, a situação é realmente muito mais grave. Segundo o Unicef (2008), essa região é responsável por $27,6 \%$ da população brasileira, sendo $31,3 \%$ de crianças na faixa etária de 0 a 6 anos. Destas, apenas 13\% na faixa etária de creche estão frequentando essa instituição. São quase quatro milhões de crianças sem acesso à Educação Infantil, devido a deficiência de equipamentos coletivos de atendimento à criança nessa faixa etária. No Nordeste existem somente 10.367 creches, 6.319 na área urbana e 4.048 na área rural, compreendendo aquelas ligadas ao setor público na esfera federal, estadual e municipal (7.148) e do setor privado (3.219), conforme dados do MEC/Inep (2006).

Em Pernambuco, o atendimento em creches e pré-escolas vem registrando uma expansão se comparado com a década de 90, contudo, distante de atender à demanda existente, particularmente na faixa etária atendida pelo MEC, 2006. Em 1991, 27.000 crianças com menos de 4 anos e 159.372 na faixa etária de 4 a 6 anos estavam matriculadas em creches e préescolas no Estado de Pernambuco. Em 2003, são registradas 23.142 crianças matriculadas em creches e 193.172 em pré-escola. Em 2006 são 1.630 estabelecimentos para atender a faixa etária de 0 a 3 anos e 7.194 para a faixa etária de 4 a 6 anos, compreendendo instituições públicas e particulares para atender uma demanda de cerca de 3 milhões de crianças (MEC / INEP, 2006).

Em Recife, existiam em 2008, 60 creches e 155 pré-escolas atendendo 16.559 crianças na faixa etária de 0 a 5 anos, longe, portanto, de atender a demanda. Conforme dados do GEAP (2008), em Recife, nesse ano, a população de 0 a 6 anos é de 154.587 crianças.

As lacunas no desenvolvimento de um modelo de atendimento pautado nos princípios de qualidade evidenciadas pela legislação vigente, inclusive pela política de Educação Infantil, são mostradas no campo da pesquisa por diferentes estudos, inclusive pelo próprio Ministério da Educação (BRASIL, 2002). 
Esse descompasso decorre da herança adquirida, e ainda não superada, ou seja, das práticas assistencialistas e compensatórias, apoiadas nos recursos da comunidade, nos programas denominados não formais, alternativos não institucionais, cujos espaços, materiais, equipamentos e recursos humanos deveriam ser disponibilizados pela comunidade, recursos que visam o barateamento dos investimentos para educação infantil (ROSEMBERG, 2002; Lima, 2016).

Estudos realizados em creches e pré-escolas da cidade e da região metropolitana do Recife, tendo em vista avaliar: o perfil dos recursos humanos e o nível de conhecimento teóricoprático acerca da função; a infraestrutura física e material; o perfil de saúde das crianças e as práticas de cuidados com estas, mostram que não existe apenas uma deficiência em termos de oferta de vagas, mas também em se tratando da infraestrutura física e material, da qualificação dos recursos humanos de nível operacional - aqueles que trabalham diretamente com a higiene, nutrição e saúde da criança - por conseguinte, quanto à qualidade dos serviços prestados à criança (LIMA, 1990; SARAIVA, 1999; SARAIVA; SILVA, 2004; ESPÍRITO SANTO; SILVA, 2004; MALAQUIAS; ALVES, 2006; LIMA, 2016).

Diante desse quadro, as alternativas que vêm sendo propostas pelos governos municipais, estaduais e federais para a solução deste problema é a privatização e a comunitarização das creches e pré-escolas, onde a população interessada deve buscar alternativas baratas, de baixo custo, sem qualidade, para dar conta desse atendimento. Das quase 35 mil creches em funcionamento no Brasil em 2006, mais da metade, aproximadamente, pertencia a organizações privadas (15,9 mil estabelecimentos), sendo grande parte ligadas a associações comunitárias, instituições filantrópicas ou organizações não-governamentais (UNCEF, 2008). Ao não ampliar a oferta, e não qualificar a prestação de serviços, o Estado induz o setor privado a fazê-lo, e este o faz de acordo com a classe.

Conforme dados do Conselho Municipal de Defesa e Promoção dos Direitos da Criança e do Adolescente - COMDICA (2009), encontram-se cadastradas 320 entidades que prestam assistência à criança de 0 a 6 anos no Recife. Dentre estas organizações, destacam-se: entidades assistenciais administradas por clubes de mães; igrejas e outras confissões religiosas e filosóficas; associações voluntárias que se configuram creches e abrigos; instituições de apoio a dependentes químicos; entidades de proteção às crianças e aos adolescentes em situação de vulnerabilidade pessoal e social, bem como de defesa dos seus direitos fundamentais. Vale salientar, ainda, uma diversidade de entidades e grupos individuais, sem fins lucrativos, que desenvolvem atividades do tipo distribuição de alimentos, sopas, leites, agasalhos, dentre outras ações pontuais e assistencialistas. 
No campo da Educação Infantil, a expansão de creches e pré-escola vem sendo realizada, por um lado, de acordo com as possibilidades que a classe pobre pode pagar, por um lugar onde o filho possa ficar "guardado" enquanto a mãe trabalha, cenário que já se tornou comum em todos os municípios do País, sendo mais corriqueiro nos centros urbanos mais desenvolvidos. A presença de profissionais sem nenhuma qualificação no exercício das funções de cuidar e educar crianças, bem como locais não apropriados ao desenvolvimento destas funções, se multiplicam a cada dia. Por outro lado, as famílias que não podem pagar por um local para deixar o filho enquanto trabalham, usufruem das estratégias criadas pelas próprias classes populares para solucionar o problema da carência de equipamentos coletivos de atendimento à criança de 0 a 6 anos, aquelas criadas pelas associações de bairros, conselho de moradores, clubes de mães, ONGs, que se configuram como verdadeiros depósitos de crianças (BRANDÃO, 2003).

Fundamentalmente, a partir de 1988, ao tempo em que ocorrem as conquistas na legislação em relação à saúde, educação e a assistência social, bem como a organização dos movimentos sociais e desenvolvimento da consciência de participação social e política dos sujeitos de direito, paradoxalmente, a ideologia neoliberal é disseminada no País, particularmente visando estabelecer o Estado Mínimo. Prevalece, desse modo, a redução crescente do papel do Estado com os gastos sociais e sua desresponsabilização com os problemas sociais, repassando à sociedade civil à responsabilidade de criar alternativas para solucioná-los, e por meio destas efetivar as conquistas legais conferidas à responsabilidade do Estado.

\section{CONSIDERAÇÕES FINAIS}

A favor da nova ordem mundial, constata-se que, apesar das conquistas e das profundas mudanças ocorridas no contexto brasileiro nos últimos 20 anos, o Estado não foi capaz de dar respostas eficazes às demandas sociais desejadas, com ânsia, pela população que se mantém excluída do mercado de trabalho, em sua maioria, ou sem acesso aos serviços coletivos básicos de qualidade, referentes à saúde, educação e assistência social. Ocorre que estrategicamente, tendo em vista a implantação do Estado Mínimo, em sentido contrário ao das conquistas sociais, o Estado vai gradativamente se distanciando do campo social. Sem investimentos, os serviços e equipamentos públicos são sucateados, tornando-se insuficientes e ineficazes no atendimento das demandas sociais.

Existe uma intencionalidade clara por parte do Estado em relação a essa questão: a transferência para a sociedade civil de ações e responsabilidades até então afetas à área estatal. 
Em outras palavras, a intenção de inserir cada vez mais o mercado e as instituições não governamentais na esfera pública estatal para atuar na área social, junto a segmentos e problemas tradicionalmente "atendidos" pelo Estado. Nesse processo, à medida que não encontra respostas às suas necessidades, a população passa a reivindicar e se organizar em busca de solução para suas necessidades fora da lógica do Estado, fomentando o surgimento e a institucionalização do Terceiro Setor.

É perceptível, particularmente, no âmbito urbano, que as contradições relacionadas a provisão dos serviços sociais coletivos de atendimento à criança têm se manifestado com especial nitidez no âmbito urbano. Contudo, apesar dessa demanda estar sempre presente, em particular nas manifestações dos movimentos sociais, os esforços para conceitualizar essas contradições ainda não têm uma tradição. Subsistem vazios teóricos consideráveis, especialmente em relação aos elementos que determinam e que se interpõem à provisão, por parte do Estado, a esses serviços. No caso dos equipamentos e serviços de atendimento à criança (unidades de educação infantil: creches e pré-escolas), embora indispensáveis à reprodução da força de trabalho e a produção e reprodução capitalista, se mostram cada vez mais difíceis de serem providos pelo Estado.

Esse é o recorte que se faz neste estudo, a partir do resgate dos avanços na legislação no campo dos direitos da criança e das mudanças na efetivação desses direitos, como expressão da relação Estado/sociedade civil. Nesse contexto, fundamentado nas estratégias neoliberais, que vêm reforçar as teses clássicas do liberalismo econômico (menos Estado e mais mercado) verifica-se que o Estado, agindo a favor dos seus próprios interesses, se mostra aliado aos interesses do grande capital. Nas três últimas décadas, o Estado abre mão de seu papel como provedor social, transferindo essa função, gradativamente, para o mercado e para as organizações que compõem o Terceiro Setor, caracterizadas como sem fins lucrativos, através do exercício da responsabilidade social.

\section{REFERÊNCIAS}

BRANDÃO, Isabel Cristina de Jesus. Políticas Públicas em Educação Infantil. 2003.

Dissertação (Mestrado em Educação) - Departamento de Educação, Universidade Federal de São Carlos, São Carlos, SP, 2003.

BRASIL. Constituição da República Federativa do Brasil. Brasília: 1988.

BRASIL. Ministério da Educação. Instituto Nacional de Estudos e Pesquisa Educacionais Sinopse da Educação Básica. 1991-2004. Brasília 2003. 64 p. 
BRASIL. Ministério da Educação. Secretária de Educação Infantil e Fundamental. Brasília: MEC. Política Nacional de Educação Infantil: pelos direitos das crianças de $\mathbf{0}$ a $\mathbf{6}$ anos à Educação, 2004 - 19 p.

BRASIL / CNE. Diretrizes Curriculares Nacionais - Educação Básica. Brasília, 2001.

BRASIL. Ministério da Educação e Desporto. INEP Senso Escolar, 2004

BRASIL, Ministério da Educação e Desporto. Secretaria de Educação Infantil e Fundamental. Padrões de infraestrutura para as instituições de educação infantil e parâmetros de qualidade para educação infantil. Brasília: MEC / Secretaria de Educação Infantil e Fundamental, 2004. 49 p.

CIVILETTI, Maria Vitória Pardal. O cuidado às crianças pequenas no Brasil escravista. Cadernos de Pesquisa, São Paulo, v. 76, p. 31-40, 1991.

COSTA, Ana Alice Alcântara. Creche Comunitária - Uma Alternativa Popular. Salvador: NEIM/UFBA; EGBA; SEC, 1981. 102p.

GOVERNO DO ESTADO DE PERNAMBUCO. Mensagem apresentada ao Congresso Legislativo na abertura da $3^{a}$ Sessão da $13^{a}$ Legislatura, pelo Governador do Estado, Dr. Estácio de Albuquerque Coimbra. Recife, 1930. 183 p.

GOVERNO DO ESTADO DE PERNAMBUCO. Exposição apresentada pelo Inventor Federal Dr. Carlos de Lima Cavalcanti à Assembleia Constituinte do Estado. Imprensa Oficial Recife, 1935. 110 p.

GOVERNO DO ESTADO DE PERNAMBUCO. Relatório das principais atividades realizadas nas diversas Secretarias de Estado e da Prefeitura de Recife, 1961. 30 p.

GOVERNO DO ESTADO DE PERNAMBUCO. Relatório das principais atividades realizadas nas diversas Secretarias de Estado e da Prefeitura de Recife, 1965. 42 p.

HADDAD, Lenira. A creche em busca de identidade - perspectiva e conflitos na construção de um projeto educativo. São Paulo: Loyola, 1991. 246 p. (coleção Realidade Educacional, 9).

PNAD. Instituto Brasileiro de Geografia e Estatística/IBGE. Pesquisa nacional por amostra de domicílios 2006 - Aspectos complementares de educação, afazeres domésticos e trabalho infantil, 2006.

LIMA, Wanessa Maria de; SARAIVA, Joseana Maria. As concepções de profissionais de Educação Infantil sobre qualidade da educação. Revista de Administração Educacional, Recife, v. 1. n. 2, p. 88-105, jul./dez. 2017.

LIMA, Wanessa Maria de. Qualidade na educação infantil no Recife como meio de consumo coletivo: discursos e práticas. Dissertação (Mestrado em Consumo, Cotidiano e Desenvolvimento Social) - Departamento de Ciências Domésticas, Universidade Federal Rural de Pernambuco, Recife, PE, 2016.

Oliveira, Zilma de Moraes Ramos de; Rossetti-Ferreira, Maria Clotilde. Propostas para o Atendimento em Creches no Município de São Paulo: histórico de uma realidade. Cadernos de Pesquisa, São Paulo, v. 56, p.39-65, fev. 1986. 
PLANO NACIONAL DE EDUCAÇÃO. Lei n.·10.172, de 2001. Senado Federal. Brasília, 2000. $173 p$.

KRAMER, Sônia. A política do pré-escolar no Brasil: A arte do disfarce. Rio de Janeiro: Dois Pontos, 1987.

KUHLMANN, Jr, Moisés. Educação pré-escolar no Brasil (1889-1922): exposição e congressos patrocinando a "assistência científica". São Paulo, 1990. Dissertação de Mestrado PUC-SP.

LIMA, Ana Maria Campello. Formação do trabalhador de creche. In: I Seminário Estadual: CRECHE UM DIREITO DA FAMÍLIA TRABALHADO UM DEVER DO ESTADO E DA SOCIEDADE. Recife: Secretaria de Educação, Cultura e Esportes do Estado de Pernambuco, 1990.

MARCÍLIO, Luíza Maria. A roda dos expostos e a criança abandonada na história do Brasil: 1726 - 1950. In: FREITAS Marcos César (organizador). História Social da Infância no Brasil. 5 ed. São Paulo: Cortez, 2003. 334 p.

MEC/INEP - Resultados do Censo Escolar, 2006

RIZZINI, Irma. Assistência à infância no Brasil. Uma análise de sua construção. Rio de Janeiro, editora da Universidade de Santa Úrsula, 1993, 193 p.

ROSEMBERG, Fúlvia. Avaliação de programas, indicadores e projetos em Educação Infantil. Revista Brasileira de Educação. SP. ANPED, n. 16, p.19-26, Jan/Fev/ Mar/Abr/2001.

ROSEMBERG, Fúlvia. A LBA, o Projeto Casulo e a Doutrina de Segurança Nacional. In: FREITAS, Marcos Cezar de (organizador). História Social da Infância no Brasil. São Paulo: Cortez, 2003, 333p.

SARAIVA, Joseana Maria. Perfil do Trabalhador do setor de nutrição e saúde de creches públicas da cidade de Recife-Pe. 1999. 178 f. Dissertação (Mestrado em Nutrição) Departamento de Nutrição, Universidade Federal de Pernambuco. Recife, PE, 1999.

SARAIVA, Joseana Maria. A lógica do capital e do Estado na provisão dos meios de consumo coletivo: uma experiência de responsabilidade social no campo da assistência à criança. Recife: Editora UFPE, 2015. 221 p.

SARAIVA, Joseana Maria. Perfil dos Trabalhadores de creches Públicas e suas concepções Acerca da Instituição. Revista Brasileira de Economia Doméstica, v.15, n. 1, p.43-59, 2004.

SARAIVA, Joseana Maria; ESPÍRITO SANTO, Antônio Carlos Gomes do; SOUZA, Nayra Luíza de Oliveira. Infraestrutura Física e Material das Creches /Pré-Escolas da RPA3. In: Relatório final da atividade de pesquisa integrante da primeira etapa do Projeto Trabalhando a Melhoria da Qualidade do Atendimento à Criança de Creches e Pré-Escola, integrante do Programa Crescer: um estudo de caso em 10 creches e pré-escola da cidade do Recife PE. Departamento de Ciências Domésticas / Universidade Federal Rural de Pernambuco. Recife, 2004.

SILVA, Jussara Tavares. Concepções de creches: o ponto de vista dos profissionais que nela atuam. 1993. 298 f. Dissertação (Mestrado em Educação: Psicologia da Educação) - Programa 
de Pós-graduação em Educação: Psicologia da Educação, Pontifícia Universidade Católica de São Paulo. São Paulo, SP. 1993.

UNICEF. Situação Mundial da Infância. Caderno Brasil, 2008.79 p

VIEIRA, Lívia Maria Fraga. A Formação do Profissional da Educação Infantil da Legislação, das Políticas e da realidade do atendimento. Secretaria Municipal de Educação. Prefeitura de Belo Horizonte, 1998. 